\title{
Análise da Qualidade da Mão de Obra na Sistemática de Trabalho nas Indústrias de Panelas Metálicas na Região do Cariri
}

\author{
Gleidson Leite de Abreu' ; Alyne Leite de Oliveira ${ }^{2}$; Hudson Josino Viana ${ }^{3}$; \\ Antonio Raniel Silva Lima ${ }^{4}$; Maria Patrícia de Alencar ${ }^{5}$
}

\begin{abstract}
Resumo: Visto que toda a sistemática de trabalho de produção de panelas metálicas é muito parecida, percebe-se que a qualidade de produtos, serviços e processos nos dias atuais deixou de ser um diferencial competitivo e transformou-se num critério qualificador, passando a ser uma ferramenta importante e praticamente obrigatória à sobrevivência organizacional, a qual as empresas necessariamente têm de desenvolver para manterem-se perenes. Desse modo, essa pesquisa teve como objetivo analisar a qualidade da mão de obra na Sistemática de Trabalho do setor produtivo da Indústria Metal-Mecânica na Região do Cariri. Caracterizou-se como de campo, do tipo exploratório com abordagem qualiquantitativa, cujo cenário foram 14 indústrias metal-mecânicas da Região do Cariri, com amostra intencional, partindo do critério de acessibilidade. Não houve abordagem com colaboradores, visto que optou-se pela observação da sistemática de trabalho, favorecendo a comparação dos dados obtidos com as entrevistas com os gestores. Os dados obtidos foram interpretados a partir da análise do discurso do sujeito coletivo para a apreensão da realidade investigada (LEFÈVRE; LEFÈVRE, 2000). A pesquisa respeitou os preceitos éticos da resolução 466/12. Obteve-se como resultado que a falta de mão de obra qualificada, a falta de conhecimento do processo e a falta do uso regular do EPI - Equipamentos de Proteção Individual, podem interferir na qualidade do produto, onde poderá ter efeito negativo diretamente na aceitação do produto no mercado, sendo que, dependendo dos custos de qualidade, o preço pode aumentar e afetar na aceitação deste, que, segundo os entrevistados, sua aceitação é ligada diretamente a preço e qualidade.
\end{abstract}

Palavras Chave: Sistemática de Trabalho. Qualidade. Industria Metal Mecânica. Panelas Metálicas.

\section{Quality analysis of Labor on Work in Systematic Steel Cookware Industry in the Region of Cariri}

\begin{abstract}
Since the whole work systematic of metal pans production are very similar, it is clear that the quality of products, services and processes nowadays is no longer a competitive advantage and has turned into a qualifier criteria, becoming an important tool and almost obligatory to organizational survival, which companies necessarily have to develop to keep up perennial. Thus, this research aimed to analyze the labor quality in work systematic of the productive sector as a competitive strategy of Metal-Mechanical Industry in the market of Ceará. It was characterized as field, exploratory and with qualiquantitative approach. Whose scenario was 14 metal-mechanical industries in the region of Cariri, with intentional sample, starting with the accessibility criteria. There was no approach with contributors, as it was decided by observing the work unsystematic, favoring the comparison of data obtained through interviews with managers. The data were interpreted by the collective subject discourse for grasping the reality investigated (LEFÈVRE; LEFÈVRE, 2000). The study followed the ethical precepts of the resolution 466/12. It was obtained as a result of the lack of skilled labor, lack of knowledge of the process and lack of regular use of PPE may affect the quality of the product, which may have negative effect directly on the acceptance of the product on the market, and depending on the quality costs, the price can increase and affect
\end{abstract}

${ }^{1}$ Graduado em Administração pelo Centro Universitário Doutor Leão Sampaio/UNILEÃO-gleidsonleite@ hotmail.com ${ }^{2}$ Especialista em Logística Empresarial, Orientadora da Graduação e Pós-Graduação da Faculdade Vale do Salgado/FVS e do Centro Universitário Doutor Leão Sampaio/UNILEÃO, membro do Comitê de Ética em Pesquisa alyneleite@leaosampaio.edu.br

${ }^{3}$ Especialista em controladoria e auditoria, professor de Marketing da Faculdade Vale do Salgado/FVS e coordenador do curso técnico em Administração da Escola Profissional Francisca de Albuquerque Moura/EPFAM-hudson.josino@gmail.com ${ }^{4}$ Professor da Graduação e Pós-Graduação da Faculdade Vale do Salgado/FVS e do Centro Universitário Doutor Leão Sampaio/UNILEÃO, Mestrando em Administração de Empresas (UNIFOR) - raniel@ leaosampaio.edu.br ${ }^{5}$ Graduada em Administração pelo Centro Universitário Doutor Leão Sampaio/UNILEÃO-patriciaalencar133@gmail.com 
acceptance of this, which according to the interviewees, their acceptance is directly linked to the price and the quality.

Keywords: Work Systematic. Quality. Industry Metal Mechanic. Metal pans.

\section{Introdução}

Por se ter acesso e certa compreensão da sistemática de trabalho em algumas indústrias na área de panelas metálicas, percebe-se que estas são praticamente iguais, o que diferencia são alguns equipamentos mais modernos nas fábricas mais antigas. Isso gera uma inquietação acerca desse cenário relacionando a aspectos como segurança de trabalho, de limpeza, de higiene, de organização, e até que ponto isso pode influenciar diretamente na qualidade do produto, já que esse produto vai direto para o consumidor final. Diante desse contexto, pretendeu-se com essa pesquisa analisar a qualidade da mão de obra na Sistemática de Trabalho do setor produtivo da Indústria de Panelas Metálicas na Região do Cariri.

Fez-se necessário para tanto, conceituar qualidade de produto e de processo; compreender a sistemática de trabalho da produção de panelas; verificar aspectos que favorecem o diferencial competitivo na conjuntura atual e identificar como a qualidade da mão de obra influencia nesse processo.

Essa pesquisa surgiu como aprendizado principalmente para o meio em que o pesquisador trabalha, tendo em vista levar como treinamento para as empresas, o que foi estudado e o que foi aprendido. Servir de base para os funcionários que trabalham para a indústria de panelas de forma que estes revejam a sua forma de trabalho, garantindo a satisfação do consumidor. E trouxe para o mundo acadêmico, estudos empíricos que poderão favorecer um "olhar" mais aprofundado à manufatura, bem como incitar este universo a estudar outras áreas de produção.

O estudo caracterizou-se como de campo, do tipo exploratório com abordagem qualiquantitativa, cujo cenário foram 14 indústrias metal-mecânicas da Região do Cariri, com amostra intencional, partindo do critério de acessibilidade. Não houve abordagem com colaboradores, visto que optou-se pela observação da sistemática de trabalho, favorecendo a comparação dos dados obtidos com as entrevistas com os gestores. Os dados obtidos foram 
interpretados a partir da análise do discurso do sujeito coletivo para a apreensão da realidade investigada.

O trabalho foi estruturado com uma abordagem inicial acerca do conceito da qualidade, adentrando qualidade do produto e determinantes da qualidade do processo produtivo, seguindo com um breve esboço acerca desta com foco em competitividade. Seguiu-se após com a metodologia e análise dos dados encontrados e propostas para pesquisas futuras.

\section{Conceituando Qualidade}

A qualidade não é algo novo, esse conceito sempre esteve na realidade humana. Antigamente o homem já se preocupava com a qualidade, visto que o homem plantava e colhia, os egípcios em suas construções de pirâmides se preocupavam com tamanho certo das pedras para usá-las. Em séculos antes de Cristo, a china com sua indústria artesanal ganhou destaque por seus produtos artesanais bem acabados, observa-se desse modo que a qualidade já estava em seus produtos, utilizados por técnicas artesanais (AILDEFONSO, 2006)

De acordo com Fonseca (1988), com o desenvolvimento e crescimento da economia, as organizações passaram a rever seus conceitos de qualidade, sentiram necessidade de melhorar, decorrente do aumento da concorrência.

Ao se buscar definição para qualidade, tem-se que Juran a define como adequação ao uso, e esta pode ser usada tanto para produto como para serviços. O mesmo se refere a um processo onde se é necessário encontrar o equilíbrio entre as características positivas e a falta de deficiências, visto que as positivas não se referem a componentes luxuosos e sim as conformidades dos produtos de acordo com as necessidades dos clientes e que produtos defeituosos causam insatisfação do mesmo. (JURAN; GODFRAY, 2000 apud OLIVEIRA, 2014)

Crosby destaca que a qualidade está associada à conformidade dos requisitos e é definida em termos quantitativos com metas a serem alcançadas, levando-se em consideração sempre a medida pelos custos da qualidade (OLIVEIRA, 2014).

Já Feigenbaum em 1922 menciona que esta está inserida nos produtos, e não pode ser medida somente com a inspeção, defende que a empresa desenvolva um Sistema de Gestão da 
Qualidade, mostrando a importância de garantir a satisfação do cliente, controlando também os custos (FEIGENBAUM, 1991 apud OLIVEIRA, 2014).

Kaoru Ishikawa, introduziu o conceito de círculo de controle de qualidade e teve grande mérito com uma ferramenta denominada "Diagrama de Causa e Efeito", de utilização fácil e que ficou conhecida com Espinha de Peixe. Esta tem como objetivo diagnosticar as possíveis causas de um problema, com vistas a resolvê-lo (OLIVEIRA, 2014).

Percebe-se então que compreender qualidade não é algo novo e que diversos estudiosos da área se voltaram para aspectos específicos não apenas com o intuito de conceitua-la, mas de, principalmente se adequar às exigências de um mercado em ascensão e mudanças constantes. Para o estabelecimento da qualidade total é fundamental o desenvolvimento de especificações precisas e exequíveis. Aqui entra a questão do desenvolvimento de produtos e o projeto de sua produção.

O processo de gerar as especificações de um produto está intimamente atrelado ao desenvolvimento do Produto. Por meio desse processo, necessidades e desejos do cliente, denominados requisitos, são transformados em especificações do produto e do processo. Tais especificações definem as características que permitirão reproduzilas. Isso implica a adequação das especificações ao ambiente operacional de produção ou aos requisitos de manufaturabilidade (NASCIMENTO, 2004 apud OLIVEIRA, 2014, p 141)

Desse modo, Lobo (2013, p. 19) destaca que qualidade é "conjunto das características de um produto ou serviço que lhe conferem aptidão para satisfazer necessidades explícitas ou implícitas". "Em muitos casos as necessidades podem evoluir com o tempo. Tal fato implica a necessidade de revisão periódica dos requisitos da qualidade".

Conclui-se então que "a qualidade, enquanto conceito, evoluiu da adequação ao padrão para a adequação às necessidades latentes dos clientes" (SHIBA et al., 1993 apud MARTINS; COSTA NETO, 1998). 


\title{
Qualidade do Produto
}

Segundo Las Casas (2006), produto pode ser definido como o objeto principal de troca, podendo ser relacionado entre pessoas físicas e jurídicas, visando a satisfação de quem consome.

O Código de Defesa do Consumidor (1990) destaca que produto é qualquer bem, móvel ou imóvel, material ou imaterial. Quando se fala de qualidade, os produtos que são colocados no mercado de consumo não acarretarão riscos á saúde ou segurança dos consumidores, com exceção daqueles que são considerados normais e previsíveis em decorrência de sua natureza e fruição, obrigando aos fornecedores informações necessárias e adequadas a seu respeito; e quando se trata de produto industrial, cabe ao fabricante prestar as informações a que se refere a informações de uso que acompanhem o produto (Lei $\mathrm{N}^{\mathrm{o}} 8078$, de 11 de setembro de 1990).

Segundo Martins; Laugeni (2005), existem diferentes focos para definir a qualidade do produto, sendo este um atributo complexo com as próprias definições, e é determinada e percebida pelo cliente. Mencionam ainda que existem oito elementos que contemplam a qualidade de um produto: Características operacionais principais, ou primárias; Características operacionais, ou secundárias; Confiabilidade; Conformidade; Durabilidade; Assistência técnica; Estética; Qualidade percebida. Essas, muitas vezes, se restringem ao uso de uma certificação.

\begin{abstract}
Sabe-se que muitas pesquisas foram realizadas no sentido de apurar a existência de uma relação entre a certificação ISO 9000 e a melhoria da qualidade do produto. Para Brown e Van Der Wiele (1995), Idris et al. (1996), Vloegeberghs e Bellens (1996), Ebrahimpour et al. (1997), Quazi e Padibjo (1998), e Brown et al. (1998) a implementação da ISO 9000 melhora a qualidade do produto. Diferentemente desses autores Motwani et al. (1996) afirmam que existe uma falsa concepção muito difundida de que a ISO 9000 implicaria em níveis mais altos de qualidade do produto. A certificação ISO não dá nenhuma garantia que a qualidade dos produtos ou serviços de uma organização é melhor que a qualidade de outras organizações. Assim, organizações certificadas pela ISO não têm automaticamente uma boa qualidade do produto (SILVA; KOVALESK; GAIA, 2012, p.58).
\end{abstract}

Mcadam e Jackson (2002, apud SILVA, KOVALESK e GAIA, 2012, p. 59) estudaram o que levava as empresas a irem em busca de uma certificação ISO 9000 e TQM. Eles observaram que as organizações que aderem à primeira tem os seguintes motivos "a) 
Demonstrar um comprometimento da qualidade para o cliente - 48\%; b) Controle e padronização dos processos - 23\%; c) Aumento da qualidade do produto - 19\%; e d) Outros 10\%”. Quanto a quem busca o TQM, os principais fatores são “a) Mecanismos para a melhoria contínua - 33\%; b) Garantia ou aumento da qualidade do produto - 24\%; c) Aumento do foco no cliente - 19\%; d) Aumento da eficiência dos negócios - 19\%; e e) Outros - 5\%".

Frente a esse contexto, percebe-se que as empresas se apropriam de métodos e técnicas para a melhoria da qualidade de produtos, processos ou serviços, mas que essas não são garantia de tal aspecto. Porém, há a necessidade de definição de atributos de acordo com o público que se almeja atender.

Espinoza e Hirano (2003, p. 100) destacam que a importância dada aos atributos depende das percepções dos indivíduos, classificando-as em seletivas ou relativas. "Podem ser seletivas, porque a atenção o é e os indivíduos têm uma tendência a filtrar as informações a que são expostos, sendo que certos elementos são retidos quando respondem às necessidades daquele momento". "As percepções podem ser relativas, porque as experiências e as expectativas dos indivíduos são diversas, sendo o grau de presença dos atributos percebido, consequentemente, de forma diferente".

Tendo em vista as mudanças ocorridas no conceito de qualidade, destaca-se a perspectiva atual no que concerne o envolvimento de todos no processo e a necessidade da qualidade total, observando os critérios definidos para tal, bem como todos os trade-offs do processo.

\section{Processo Produtivo: Determinantes da Qualidade}

Ao se observar que a organização busca atender as expectativas dos consumidores no que diz respeito aos fatores de qualidade por ele esperado, tem-se como aspecto fundamental o processo produtivo do mesmo.

A função produção, segundo Slack (2002, p.38) "é central para a organização porque produz os bens e serviços que são a razão de sua existência, mas não é a única nem, necessariamente, a mais importante".

O autor supracitado (p. 39) ainda destaca que: 
Existem dois tipos de recursos de transformação que formam os "blocos de construção" de todas as operações: instalações- prédios, equipamentos, terreno e tecnologia do processo de produção; funcionários- os que operam, mantêm, planejam e administram a produção. (Note que usamos o termo funcionários para descrever todas as pessoas envolvidas na produção, em todos os níveis (grifo nosso) (SLACK, 2002, p. 39).

Esses fatores associados contribuem para a eficácia do processo organizacional. Nesse contexto, Macedo (2012, p.1) menciona que "sem produtividade ou eficiência do processo produtivo, dificilmente a empresa vai ser bem sucedida ou até mesmo sobreviver no mercado". O mesmo também cita que "a produtividade vem sendo percebida mais como uma medida de eficiência do processo de produção do que do processo produtivo de uma empresa" (p. 2).

Nesse contexto, a mão de obra especializada é de grande importância para o sucesso ou fracasso do negócio, porém algumas empresas contratam e selecionam os colaboradores pensando no salário mais baixo. Dessa forma a organização tem certa economia, mas em médio prazo, o aumento dos custos devido a baixa produtividade, falta de qualidade, ausências e pequeno tempo de permanência do funcionário, causam uma despesa desnecessária (SEBRAE, 2015).

Segundo G1 (2012) “mão de obra qualificada é o trabalhador que tem as qualidades mínimas exigidas para exercer a função para a qual ele está sendo contratado. Desde a mais simples até a mais sofisticada".

Mas muitas vezes o empresário prefere não capacitar o colaborador, acreditando que este vai se desligar rapidamente da empresa e todo o investimento foi perdido, porém o que se percebe é que um funcionário qualificado compensa o valor investido em sua capacitação e pode contribuir para a sua permanência na mesma (SEBRAE, 2015).

Sempre na contratação do funcionário, este deverá ser apresentado aos outros funcionários e aos setores, ter um conhecimento da empresa, do produto que vai trabalhar e sempre acompanhá-lo no desenvolvimento e treiná-lo.

O colaborador que tem habilidades para atuar na profissão e que passa por treinamentos constantes, além de contribuir para o aumento do desempenho da empresa, estará mais engajado, no entanto “dos 192 milhões de brasileiros, 93 milhões estão aptos a trabalhar [...] Esse descompasso está entre o que essas pessoas oferecem e o que o mercado de trabalho precisa" (G1, 2012). 
Quadro 01: Efeitos que mais pesam para a indústria.

\begin{tabular}{|l|l|l|}
\hline $\begin{array}{l}\text { O que é mais afetado com a falta de mão de } \\
\text { obra qualificada? }\end{array}$ & $\begin{array}{l}\% \text { das empresas } \\
(2013)\end{array}$ & $\begin{array}{l}\% \text { das } \\
\text { empresas } \\
(2011)\end{array}$ \\
\hline Produtividade & $74 \%$ & $69 \%$ \\
\hline Qualidade & $61 \%$ & $63 \%$ \\
\hline Expansão da produção & $39 \%$ & $40 \%$ \\
\hline Gerenciamento da produção & $28 \%$ & $28 \%$ \\
\hline Manutenção dos equipamentos & $24 \%$ & $21 \%$ \\
\hline Aquisição de novas tecnologias & $22 \%$ & $22 \%$ \\
\hline Ampliação das vendas & $20 \%$ & $23 \%$ \\
\hline Desenvolvimento de novos produtos & $20 \%$ & \\
\hline
\end{tabular}

Fonte: Souza (2013).

O quadro acima destaca o que vem sendo descrito nessa pesquisa com relação aos benefícios trazidos pela gestão da qualidade em consonância com a produtividade em função do uso da mão de obra qualificada.

\section{Gestão da Qualidade para um Diferencial Competitivo}

Segundo Oliveira (2014), a qualidade de produtos, serviços e processos deixou de ser um diferencial competitivo e passou a ser uma ferramenta importante e obrigatória para a sobrevivência da empresa, visto que diversos fatores levaram a essa mudança, tais como o aumento da competitividade, a globalização de mercados, conscientização dos consumidores em relação aos seus direitos, a alta informatização da empresa entre outras mais.

Já para Hill \& Jones (2011 apud SILVA; SARAIVA, 2012, P.3) "uma instituição constrói vantagem competitiva quando conjuga quatro fatores: eficiência, qualidade, inovação e capacidade de resposta ao cliente". 
Observa-se, assim que a qualidade em si, pode não ser alvo de diferencial, porém o gerenciamento desta em prol de u conjunto de fatores que agreguem redução de custos e eficiência na resposta ao consumidor podem favorecer esse diferencial tão almejado pelas empresas.

Hitt (2008 apud COSTA, NASCIMENTO e PEREIRA, 2015, p. 9) destaca essa ideia quando menciona que no cenário atual as empresas devem entender que os esforços para a competitividade são diversos e a possibilidade de fracasso está em pé de igualdade com o sucesso. Se faz necessário, dessa forma, que os gestores adotem tanto uma mentalidade, como medidas que "valorizem a flexibilidade, a velocidade, a inovação, a integração e os desafios que surgirem como resultados das constantes mudanças”.

\section{Metodologia}

A pesquisa caracterizou-se como de campo, do tipo exploratório com abordagem qualiquantitativa. Segundo Bogdan e Biklen (1982) a abordagem qualitativa permite o contato direto do pesquisador com a situação estudada, a partir da apreensão da realidade diante da interação com os autores envolvidos. A abordagem qualitativa evidencia a perspectiva social como uma abrangência de significados e tem a possibilidade de múltiplas investigações (MINAYO; SANCHES, 1993). Ainda segundo Minayo e Sanches (1993, p. 245), “a abordagem qualitativa só pode ser empregada para a compreensão de fenômenos específicos e delimitáveis mais pelo seu grau de complexidade interna do que pela sua expressão quantitativa". Já a quantitativa, segundo Dalfovo; Lana; Silveira (2008, p. 06) consideram "tudo que pode ser mensurado em números, classificados e analisados".

O cenário da pesquisa foi as indústrias metal-mecânicas da Região do Cariri. A indústria de panelas metálicas no Cariri vem crescendo gradativamente nos últimos 15 anos, se tornando um grande polo potencial na indústria nacional.

Os sujeitos da pesquisa foram os gestores e funcionários das empresas destacadas no quadro abaixo. A amostra foi intencional, composta por 18 gestores, partindo do critério de acessibilidade. Quanto aos colaboradores, não houve abordagem a nenhum deles, visto que optou-se pela observação da sistemática de trabalho, favorecendo a comparação dos dados obtidos com as entrevistas. 
Quadro 2: Objetos de Estudo

\begin{tabular}{|c|c|c|c|c|c|}
\hline EMPRESA & LOCAL & GESTORES & $\begin{array}{l}\text { TEMPO DE } \\
\text { EMPRESA }\end{array}$ & $\begin{array}{c}\text { QTD } \\
\text { FUNCIONARIOS }\end{array}$ & $\begin{array}{l}\text { QTD FUNC } \\
\text { PRODUÇÃO }\end{array}$ \\
\hline $\begin{array}{l}\text { Alumínio } \\
\text { Prollar } \\
\end{array}$ & $\begin{array}{c}\text { Juazeiro do } \\
\text { Norte }\end{array}$ & Nivaneide & 21 Anos & 130 & 110 \\
\hline $\begin{array}{l}\text { Alumínio } \\
\text { Luminex }\end{array}$ & $\begin{array}{l}\text { Juazeiro do } \\
\text { Norte }\end{array}$ & Italo & 19 Anos & 100 & 30 \\
\hline $\begin{array}{l}\text { Alumínio } \\
\text { Aluminela }\end{array}$ & $\begin{array}{l}\text { Juazeiro do } \\
\quad \text { Norte }\end{array}$ & Batista & 04 Anos & 40 & 35 \\
\hline $\begin{array}{l}\text { Alumínio } \\
\text { Adenox }\end{array}$ & $\begin{array}{l}\text { Juazeiro do } \\
\text { Norte }\end{array}$ & Adelaido & 14 Anos & 65 & 60 \\
\hline $\begin{array}{l}\text { Alumínio } \\
\text { Alumil }\end{array}$ & $\begin{array}{l}\text { Juazeiro do } \\
\text { Norte }\end{array}$ & Mirialdo & 10 Anos & 18 & 14 \\
\hline $\begin{array}{l}\text { Alumínio } \\
\text { Bauxita }\end{array}$ & $\begin{array}{l}\text { Juazeiro do } \\
\quad \text { Norte }\end{array}$ & Elias & 8 Anos & 15 & 12 \\
\hline Alumínio Lins & $\begin{array}{l}\text { Juazeiro do } \\
\text { Norte }\end{array}$ & Neto / Laécio & 9 Anos & 35 & 28 \\
\hline $\begin{array}{l}\text { Alumínio } \\
\text { Dena }\end{array}$ & $\begin{array}{l}\text { Juazeiro do } \\
\quad \text { Norte }\end{array}$ & Veruska & 7 Anos & 30 & 20 \\
\hline $\begin{array}{l}\text { Alumínio } \\
\text { Dular }\end{array}$ & $\begin{array}{l}\text { Juazeiro do } \\
\text { Norte }\end{array}$ & Hans & 3 anos & 50 & 43 \\
\hline $\begin{array}{l}\text { Alumínio } \\
\text { Luxlar }\end{array}$ & $\begin{array}{l}\text { Juazeiro do } \\
\text { Norte }\end{array}$ & Alesson & 6 Anos & 20 & 12 \\
\hline Alumic & Crato & Dawin & 23 Anos & 70 & 50 \\
\hline $\begin{array}{l}\text { Alumínio } \\
\text { Luminox }\end{array}$ & Crato & Neves Junior & 22 Anos & 35 & 33 \\
\hline $\begin{array}{l}\text { Alumínio } \\
\text { Roque }\end{array}$ & Crato & Roque & 18 Anos & 102 & 87 \\
\hline $\begin{array}{l}\text { Alumínio } \\
\text { Corbã }\end{array}$ & Iguatu & Aginélio & 13 Anos & 290 & 280 \\
\hline
\end{tabular}

Fonte: Dados da Pesquisa (2015)

A coleta de dados foi feita através de entrevista semiestruturada e observação assistemática não participante. A entrevista "[...] favorece não só a descrição dos fenômenos sociais, mas também sua explicação e a compreensão de sua totalidade [...]" além de manter a presença consciente e atuante do pesquisador no processo de coleta de informações (TRIVIÑOS, 1987, p. 152). A observação assistemática prevê o recolhimento e registro dos fatos da realidade sem que o pesquisador faça uso de meios técnicos especiais ou faça perguntas 
diretas ao pesquisado. Tanto a observação assistemática quanto a não-participante são técnicas utilizadas em estudos exploratórios, que independem de planejamento e controle precisamente elaborados para que sejam executados (MARCONI; LAKATOS, 1999; RICHARDSON, 1999).

A análise dos dados obtidos na entrevista passou por uma análise interpretativa. Utilizando-se da análise do discurso do sujeito coletivo para a apreensão da realidade investigada. A técnica do Discurso do Sujeito Coletivo-DSC (LEFÈVRE; LEFÈVRE, 2000) sugere a organização e tabulação de dados qualitativos de natureza verbal, obtidos de depoimentos estando fundada na teoria da Representação Social e seus pressupostos sociológicos. O DSC é uma modalidade de apresentação de resultados de pesquisas qualitativas, que apreende os depoimentos como matéria prima, visando expressar o pensamento de uma coletividade com base em um ou vários discursos-síntese.

O presente estudo está de acordo com a resolução 466/12 do Conselho Nacional de Saúde que normatiza as pesquisas com seres humanos. Todos os sujeitos assinaram o termo de consentimento livre esclarecido.

\section{Análise e Discussão dos Resultados}

Quando se está falando do ramo de alumínio, numa economia economicamente instável, observa-se uma preocupação muito grande de empresários. Mas também existe uma movimentação no SIMEC - Sindicato das Indústrias Metalúrgicas Mecânicas e de Material Elétrico, um sindicado dinâmico com sede em Fortaleza e com representatividade nos interiores do Ceará, como Juazeiro do Norte e Sobral, onde foi observado uma aproximação com o Governo do Estado do Ceará, assim com as Secretarias de Infraestrutura e Desenvolvimento, a fim de melhorar o ramo e trazer tecnologia e inovação, já que a região do Cariri é o segundo setor mais importante para a economia da região, depois do ramo de calçados, a produzir emprego e renda.

Segundo dados do Simec (2015) no Cariri, ainda nos dias de hoje existem muitas empresas informais, que acabam ficando para trás quando se fala de crescimento, de inovação, de qualidade, de redução de custos, de leis e portarias essenciais para o desenvolvimento das micro e pequenas empresas, pois hoje a região conta com 28 empresas associadas, mas também 
com mais de 50 empresas informais. Estas ficam ultrapassadas quando se fala da importância que são as informações nos dias de hoje, e ao se falar de Ceará tem-se mais de 100 empresas entre as formais e informais, o que se torna de grande preocupação para uma região tão grande quanto o Ceará, que tem que acompanhar o desenvolvimento do Nordeste. E ao se falar em Brasil, observa-se por todo nordeste, empresários se movimentando no setor com investimentos altíssimos dentro do próximo negócio.

Diante do contexto mencionado, as entrevistas feitas com os gestores foram analisadas de forma interpretativa e categorizadas, conforme o método escolhido para tal. Porém não se deu destaque associando os nomes das empresas a cada discurso, conforme solicitação dos mesmos. O tratamento quantitativo analisou a frequência dos depoimentos de acordo com a ideia central. O uso do gravador favoreceu a coleta de dados, trazendo a possibilidade do detalhamento das respostas de cada objeto de pesquisa. Para essa análise destacou-se expressões chave e separadas as ideias centrais dessas expressões para delineamento do discurso dos sujeitos pesquisados. Esse método de pesquisa se dá desde 1990, conforme cita Mota, Melo e Paixão (2012), e que tem ênfase e origem nas ciências da saúde a partir de 2005, mas já tem tido destaque nas ciências humanas e sociais aplicadas.

Quadro 3: Ideia Central A.

\section{IC-A QUALIDADE É TER UM PRODUTO QUE ATENDA ÀS NECESSIDADES}

Discurso do Sujeito Coletivo: Qualidade é ter um produto finalizado, que esteja dentro da legislação vigente, tendo em vista o acompanhamento da produção deste e engajamento dos colaboradores. Tem também que estar “em conformidade com o acabamento", porém livre de defeitos, bonito e que traga benefícios, agregando valores, tendo em vista questões de sobrevivência.

\begin{tabular}{|c|c|c|c|}
\hline Tema & Exemplos de Verbalizações & Qtd. & $\%$ \\
\hline \multirow{8}{*}{$\begin{array}{l}\text { Conceito de } \\
\text { Qualidade }\end{array}$} & É ter um produto bem acabado & 3 & $21 \%$ \\
\hline & Produzir um produto dentro da lei & 1 & $7 \%$ \\
\hline & Ter bons serviços de vendas e pós-vendas e produtos bem acabados & 1 & $7 \%$ \\
\hline & $\begin{array}{l}\text { Qualidade do produto é quando se tem um acompanhamento da } \\
\text { produção aonde os colaboradores, em conjunto, proporcionam destaque } \\
\text { no produto }\end{array}$ & 3 & $21 \%$ \\
\hline & $\begin{array}{l}\text { É a satisfação do cliente com o produto adquirido em conformidade e } \\
\text { com acabamento }\end{array}$ & 3 & $21 \%$ \\
\hline & Produto sem defeito & 1 & $7 \%$ \\
\hline & Produto mais bonito, acessível e com benefício & 1 & $7 \%$ \\
\hline & Questão de sobrevivência & 1 & $7 \%$ \\
\hline
\end{tabular}

Fonte: Dados da Pesquisa (2015). 
Os discursos descritos acima destacam as categorias analisadas, conforme as Ideias centrais (IC's) exploradas.

Tendo em vista a IC o que é ter um produto de qualidade, os gestores mencionaram o DSC, conforme destacado no quadro abaixo, seguido de exemplos de verbalizações individuais que destacavam expressão chave "qualidade do produto".

É perceptível que o discurso central gira em torno de um produto conforme as especificações, fato esse evidenciado e muito estudado pelos teóricos. Quanto à sistemática de trabalho, fica evidenciado a influência do trabalho destes no bom desempenho do produto, conforme DSC abaixo.

A observação assistemática não participante, também proposta por essa pesquisa, feita junto aos processos produtivos, deixou claro que toda a sistemática de trabalho de produção de panelas metálicas, são muito parecidas, algumas diferenciadas pela questão da tecnologia usada, outras utilizadas pela que usam ante aderente, outras por pintura externa.

O primeiro passo do processo é de carimbar o disco de alumínio, logo após utilizando a uma Máquina de Prensa Hidráulica ou Torno Repuxo para bater os discos e começar a ter as primeiras formas das panelas. Após esse processo, a panela vai para uma máquina de refilar onde essa máquina pode tirar o excesso e fazer o acerto do tamanho correto da panela. Em seguida, passa pela máquina de fazer o cordão, que dependendo no próprio torno repuxo esse cordão já pode ser feito evitando assim passar pelo refilo e o cordão.

Algumas empresas utilizam a máquina de usinagem, onde fazem uma usinagem no fundo da panela, evitando que a panela escorregue no fogão, que são espirais no fundo da mesma. Depois disso vem o lixamento interno, seguido da politriz, onde é feito o polimento externo do produto. Caso tenha-se optado pela pintura da panela, esse processo não é utilizado, o produto vai direto para a cabine de pintura, chamada pintura eletrostática.

Antes de ir para o processo de montagem, parte desse é feito também com a tampa que passa pela Prensa Hidráulica ou Torno Repuxo, a máquina de fazer cordão e caso a tampa passe somente pelo processo de torno repuxo, esta ainda passa por uma prensa de fazer furos na tampa.

Após todo esse processo os dois produtos, corpo e tampa, chegam no processo de montagem, onde o corpo da panela passa pelo processo de arrebitamento de suportes, logo após parafusar cabo ou alça, no caso da tampa, parafusar o pomel, junta os dois aonde se forma a 
panela, é etiquetado, colocado código de barras e em seguida é formado ou não, dependendo da empresa, jogos de panelas. Este poderá ser shrinkado, plastificado ou colocado em caixa, enviado para a estoque e logo após expedição.

Quadro 4: Ideia Central B.

\section{IC-B SISTEMÁTICA DE TRABALHO}

Discurso do Sujeito Coletivo: A sistemática de trabalho é um processo em que a empresa envolve os colaboradores com o objetivo de melhoria, de acordo com os padrões existentes, porém com certificação apenas para alguns itens ou com a busca desta em andamento. Para que o processo ocorra de forma correta é feita inspeção por setores, por colaboradores ou em laboratório de análise. Para que isso ocorra de forma satisfatória, são entregues EPI's, mesmo que para o uso ainda ocorram restrições por parte dos colaboradores. Tendo em vista que o produto saia com a qualidade desejada, não se foca em controle deste no cliente final.

\begin{tabular}{|c|c|c|c|}
\hline Tema & Exemplos de Verbalizações & Qtd. & $\%$ \\
\hline \multirow{3}{*}{$\begin{array}{l}\text { Análise do } \\
\text { Processo }\end{array}$} & Com orientação dos colaboradores (durante o processo) & 4 & $29 \%$ \\
\hline & Com inspeção (por setores, por colaboradores, visual ou mecânica) & 8 & $57 \%$ \\
\hline & Laboratorio Analise & 2 & $14 \%$ \\
\hline \multirow{2}{*}{ Uso de EPI's } & Sim, porém os colcaboradores usam com muita restrições. & 12 & $86 \%$ \\
\hline & Sim, Entregues Cobrados e Controlados & 2 & $14 \%$ \\
\hline \multirow{3}{*}{$\begin{array}{c}\text { Produto } \\
\text { exposto no } \\
\text { Cliente } \\
\end{array}$} & Não & 10 & $71 \%$ \\
\hline & Sim (promotor de vendas & 1 & $7 \%$ \\
\hline & Sim ( pelo representante) & 3 & $21 \%$ \\
\hline \multirow{3}{*}{ Certificação } & Não (mais está em andamento) & 5 & $36 \%$ \\
\hline & Sim (Panela de pressão) & 5 & $36 \%$ \\
\hline & Não & 4 & $29 \%$ \\
\hline
\end{tabular}

Fonte: Dados da Pesquisa (2015).

No que se refere à influencia da qualidade do trabalho nos resultados almejados, observou-se que existe pouca preocupação com a capacitação do colaborador, muitas vezes é ensinado o trabalho no momento em que este assume o setor, que existe uma dificuldade da empresa em fazer com que o colaborador utilize o equipamentos de segurança, como todo o trabalho é manual e a inspeção é visual, a falta de análise critica do colaborador pode afetar no fabricação de um produto de qualidade, fato esse confirmado com o discurso descrito no quadro que segue. 
Quadro 5: Ideia Central C.

\section{IC-C INTERFERÊNCIA DA QUALIDADE DO TRABALHO NOS RESULTADOS DA EMPRESA}

\begin{tabular}{|c|c|c|c|}
\hline \multicolumn{4}{|c|}{$\begin{array}{l}\text { Discurso do Sujeito Coletivo: Para se ter um produto de qualidade, os colaboradores precisam contribuir com o } \\
\text { processo, sendo qualificado e motivado e havendo vistoria dos produtos e insumos, pois a qualidade desse } \\
\text { processo influencia positiva ou negativamente no resultado final, dependendo do envolvimento da equipe. }\end{array}$} \\
\hline Tema & Exemplos de Verbalizações & Qtd. & $\%$ \\
\hline \multirow{3}{*}{$\begin{array}{l}\text { Interferência } \\
\text { na qualidade } \\
\text { do produto }\end{array}$} & Sim (com certeza) & 12 & $86 \%$ \\
\hline & Sim (deve haver vistoria dos produtos e insumos) & 1 & $7 \%$ \\
\hline & Sim (sendo qualificado e motivado) & 1 & $7 \%$ \\
\hline \multirow{5}{*}{$\begin{array}{l}\text { Interferência } \\
\text { nas vendas }\end{array}$} & sim (a qualidade dos produtos interferem nas vendas) & 10 & $71 \%$ \\
\hline & Sim (os clientes necessitam de qualidade dos produtos) & 1 & $7 \%$ \\
\hline & Sim (o mercado exige) & 1 & $7 \%$ \\
\hline & Sim (sem dúvida) & 1 & $7 \%$ \\
\hline & $\begin{array}{l}\text { Sim (porém existem caso em que o cliente busca preço como diferencial } \\
\text { competitivo) }\end{array}$ & 1 & $7 \%$ \\
\hline
\end{tabular}

Fonte: Dados da Pesquisa (2015).

O produto entregue ao mercado é consequência de um processo produtivo eficiente e eficaz, cuja sistemática de trabalho seja coerente com esses fatores. A IC descrita abaixo destaca o amplo ramo de atuação das indústrias pesquisadas e destaca que as mesmas dão importância à sua manutenção no mercado, realizando os procedimentos necessários à troca ou conserto do produto com falha.

Quadro 6: Ideia Central D.

\section{IC-D CONTROLE DA QUALIDADE DO PRODUTO NO MERCADO}

Discurso do Sujeito Coletivo: Os setores de abrangência são diversos, desde crediaristas até o atacado. O contato com o cliente ocorre em sua maioria através de contato telefônico, e quando observado algum defeito, procuramos substituir ou consertar a mercadoria.

\begin{tabular}{|c|l|c|c|}
\hline \multicolumn{1}{|c|}{ Tema } & \multicolumn{1}{|c|}{ Exemplos de Verbalizações } & Qtd. & \% \\
\hline \multirow{2}{*}{$\begin{array}{c}\text { Setor de } \\
\text { Atuação }\end{array}$} & Crediarista & 7 & $50 \%$ \\
\cline { 2 - 4 } & Crediário, Varejo, Logística, Feirantes e Representantes & 6 & $43 \%$ \\
\cline { 2 - 4 } & Atacado & 1 & $7 \%$ \\
\hline \multirow{2}{*}{$\begin{array}{c}\text { Contato } \\
\text { com o } \\
\text { cliente }\end{array}$} & Tratativa de reclamação de cliente (através do site, via telefone ou e mail) & 7 & $50 \%$ \\
\cline { 2 - 4 } & Solicita, ao cliente, o esclarecimento do produto e busca solucionar o problema & 2 & $14 \%$ \\
\cline { 2 - 4 } & Não possui nenhum procedimento & 1 & $7 \%$ \\
\hline & Corrige o erro e repõe a mercadoria & 6 & $43 \%$ \\
\hline
\end{tabular}




\begin{tabular}{|c|l|c|c|} 
Tomada de & Substitui o produto e/ou conserta & 4 & $29 \%$ \\
\cline { 2 - 4 } Decisão & & & \\
frente a & & & \\
uma & Verifica o defeito (se foi do processo e/ou fornecedor) e busca solucionar o & 4 & $29 \%$ \\
reclamação & problema
\end{tabular}

Fonte: Dados da Pesquisa (2015).

Em consonância a esse fato, a observação junto aos colaboradores destacou que, quando é tido qualquer tipo de devolução do produto por conta de uma baixa qualidade ou defeito, é feito uma reunião com os colaboradores, para verificar o que foi que aconteceu, podendo em alguns casos, o mesmo ser mudado de setor ou até mesmo ser demitido, gerando assim uma atenção a mais no setor produtivo e uma insegurança por parte do setor.

\section{Considerações Finais}

Todos os entrevistados acreditam que quando se fala de qualidade, a palavra é ligada a produto, satisfação do cliente, bons serviços de vendas e pós-vendas, mas nenhum deles ressalta a importância da qualidade na mão de obra.

Visto que o ramo de panelas metálicas das empresas do Cariri ainda utiliza a manufatura como meio de fabricação do produto, e utiliza-se da inspeção visual para a conformidade do produto, não foi evidenciado a importância da qualidade de mão de obra qualificada ou conscientização do colaborador como ferramenta da qualidade no produto, mas, quando foi perguntado na entrevista se a qualidade de trabalho poderia interferir na qualidade do produto, todos foram unanimes, ressaltando a importância da mão de obra na produção.

De acordo com a pesquisa realizada, foi constatado que a mão de obra qualificada, e do uso correto dos EPI's, interfere na qualidade do produto, podendo interferir na aceitação no comércio. O consumidor está consciente de seu direito, exige preço e qualidade, e quando falase de qualidade, para alguns empresários do ramo, liga-se o nome a custos, mas que é visto após esse estudo que qualidade e preço podem andar juntos, pois inicialmente, existe um investimento em qualidade, seja por meios de ferramentas da qualidade, seja por meios de certificação, principalmente quando a certificação é compulsória, mas se a qualidade for 
implantada de forma correta, e se houver investimentos na mão de obra qualificada, o que os empresários chamam de custos, poderá ser chamado de ganho.

Quando se fala de competitividade no ramo de panelas metálicas, aquele que tem melhor preço e melhor qualidade do produto, estará no mercado, mas sempre sendo visível primeiro a qualidade do produto.

Como optou-se pela observação da sistemática de trabalho, é fato de que o colaborador mais ligado diretamente à produção, elaboração e o empacotamento do produto, está mais próximo do cliente do que o gestor, sendo assim, tendo a necessidade de investimentos na mão de obra qualificada para atender a necessidade do cliente e a qualidade do produto, bem como melhorar as condições de trabalho, EPI'S corretos e cobrados, tudo isso para melhorar a saúde do trabalhador e resultados esperados pela empresa, contemplando assim o objetivo proposto pela pesquisa.

Para estudos posteriores, sugere-se a aplicabilidade de ferramentas da qualidade, dado o envolvimento dos colaboradores e gestores no desempenho destas, tendo em vista redesenhos de processos, visando inclusive a adequação a certificações posteriores.

\section{Referências}

AILDEFONSO, E. C. Gestão da qualidade. 2006. Disponível em: <www.cefetes.br/cursos/>. Acesso em: 26 set. 2015.

BURNIER, José Roberto. GONÇALVES, Antonio. Dificuldade de encontrar mão de obra qualificada afeta economia brasileira. G1. Jornal Nacional. Disponível em: <http://g1.globo.com/jornal-nacional/noticia/2012/08/dificuldade-de-encontrar-mao-de-obraqualificada-afeta-economia-brasileira.html>. Acesso em: 29 out. 2015.

Conselho Nacional de Saúde (Brasil). Resolução n o 466, de 12 de dezembro de 2012. Brasília, 2012 [citado 2014 Mar 11]. Disponível em:

<http://www.conselho.saude.gov.br/web_comissoes/conep/index.html>. Acesso em: 17 out. 2015.

COSTA, Everton Francisco; NASCIMENTO, Renato Nunes do; PEREIRA, Fernando da Silva. Gestão da Qualidade: A Qualidade como fator de Competitividade e Satisfação do Cliente. Disponível . Acesso em: 08 nov. 2015. 
DALFOVO, Michael Samir; LANA, Rogério Adilson; SILVEIRA, Amélia. Métodos Quantitativos e Qualitativos: Um resgate teórico. Revista interdisciplinar Científica Aplicada, Blumenau, v.2, n.4, p.01-13, Sem II. 2008. ISSN1980-7031. Disponível em:

$<$ http://www.unisc.br/portal/upload/com_arquivo/metodos_quantitativos_e_qualitativos_um_r esgate_teorico.pdf >. Acesso em: 10 nov. 2015.

ESPINOZA, Francine da Silveira; HIRANO, Adriana Shizue. As Dimensões de Avaliação dos Atributos Importantes na Compra de Condicionadores de Ar: um Estudo Aplicado. 2003.

Revista de Administração Contemporânea/RAC. Disponível em:

<http://www.scielo.br/pdf/rac/v7n4/v7n4a06.pdf>. Acesso em: 10 nov. 2015.

GAITHER, Norman; FRAZIER, Greg. Administração da Produção e Operações. $8^{a}$ ed. Cengage Learning, 2002.

LEFÈVRE, F.; LEFÈVRE, A. M. C; TEIXEIRA, J. J. V. O discurso do sujeito coletivo: uma nova abordagem metodológica em pesquisa qualitativa. Caxias do Sul: EDUCS, 2000.

LÜDKE. M; ANDRÉ. M. E. D. A. Pesquisa em educação: abordagem qualitativa. $2^{\text {a }}$ ed. Rio de Janeiro: E.P.U, 2013.

MARCONI, M. de A. \& LAKATOS, E. V. Técnicas de pesquisa: planejamento e execução de pesquisas, amostragens e técnicas de pesquisas, elaboração, análise e interpretação de dados. $4^{\text {a }}$ ed amp. e rev. São Paulo: Atlas, 1999.

MARTINS, R. A.; COSTA NETO, P.L.O. Indicadores de Desempenho para a Gestão pela Qualidade Total: Uma Proposta de Sistematização. Gestão \& Produção v.5, n.3, p. 298-311, dez. 1998. Disponível em: <http://www.scielo.br/pdf/gp/v5n3/a10v5n3.pdf>. Acesso em: 10 nov. 2015.

MARTINS, Petrônio G.; LAUGENI, Fernando Piero. Administração da Produção. 2a ed.rev.,aum. e atual - São Paulo: Saraiva, 2005.

MINAYO, M. C. de S.; SANCHES, O. Quantitativo-Qualitativo: Oposição ou Complementaridade? Caderno de Saúde Pública. Rio de Janeiro, 9 (3): 239-262, jul/set, 1993.

NUNES; NÓBREGA-THERRIEN; FARIAS (Org.). Pesquisa científica para iniciantes: caminhando no labirinto. Fortaleza: EdUECE, 2011.

OLIVEIRA, Otávio J. Curso Básico de Gestão da Qualidade. - São Paulo: Cengage Learning, 2014.

PALADINI, Edson Pacheco; CARVALHO, Marly Monteiro de. Gestão da Qualidade Teoria e Casos. $2^{\mathrm{a}}$ ed. - Rio de Janeiro: Elsevier: ABEPRO,2012.

PORTAL DA LEGiSlaÇÃO. Código de Defesa do Consumidor. Disponível em: <http://www4.planalto.gov.br/legislacao/legislacao-1/codigos-1>. Acesso em: 09 nov. 2015. 
RICHARDSON, R. J. Pesquisa Social: métodos e técnicas. São Paulo: Atlas, $3^{\text {a }}$ ed. rev. e ampl., 1999.

SEBRAE. A Importância da mão de Obra Qualificada. Disponível em: <http://www.sebrae.com.br/sites/PortalSebrae/artigos/A-import\%C3\%A2ncia-dam\%C3\%A3o-de-obra-qualificada>. Acesso em: 08 nov. 2015.

SILVA, Luan Carlos Santos; KOVALESKI, João Luiz; GAIS, Silvia. Gestão da qualidade do produto no processo de produção industrial: um estudo de caso em uma indústria de bebidas. Revista de Engenharia e Tecnologia. Disponível em: <http://www.revistaret.com.br/ojs2.2.3/index.php/ret/article/viewFile/98/138>. Acesso em: 08 nov. 2015.

SILVA, Sónia; SARAIVA, Margarida. Gestão da Qualidade como diferencial competitivo na Satisfação e Fidelização de clientes. Disponível em: <https://dspace.uevora.pt/rdpc/bitstream/10174/5430/1/A\%20Gest\%C3\%A3o\%20da\%20Qual idade $\% 20$ como $\% 20$ diferencial $\% 20$ competitivo $\% 20$ na $\% 20$ Satisfa $\%$ C3\%A7\%C3\%A3o\%20e $\% 20$ Fideliza\%C3\%A7\%C3\%A3o\%20de\%20clientes_Silva.Saraiva.pdf $>$. Acesso em: 08 nov. 2015.

SOUZA, Beatriz. Os efeitos para a indústria da pouca mão de obra qualificada. 2013. Revista Exame.com. Disponível em: <http://exame.abril.com.br/economia/noticias/os-piores-efeitosda-falta-de-mao-de-obra-qualificada>. Acesso em: 10 nov. 2015.

TRIVIÑOS, A. N. S. Introdução à pesquisa em ciências sociais: a pesquisa qualitativa em educação. São Paulo: Atlas, 1987.

Como citar este artigo (Formato ABNT):

ABREU, Gleidson Leite de; OLIVEIRA, Alyne Leite de; VIANA, Hudson Josino; LIMA, Antonio Raniel Silva; ALENCAR, Maria Patrícia de. Análise da Qualidade da Mão de Obra na Sistemática de Trabalho nas Indústrias de Panelas Metálicas na Região do Cariri. Id on Line Rev.Mult. Psic., 2018, vol.12, n.41, p.294-312. ISSN: 1981-1179.

Recebido: $14 / 06 / 2018$

Aceito 25/06/2018 